\title{
Unstructured CFD and Noise Prediction Methods for Propulsion Airframe Aeroacoustics
}

\author{
S. Paul Pao ${ }^{1}$, Khaled S. Abdol-Hamid ${ }^{1}$, Richard L. Campbell ${ }^{1}$, Craig A. Hunter ${ }^{2}$ \\ NASA Langley Research Center, Hampton, Virginia 23681, USA
}

Steven J. Massey ${ }^{3}$

Eagle Aeronautics, Inc., Hampton, Virginia 23666, USA

and

\author{
Alaa A. Elmiligui ${ }^{4}$ \\ Analytical Services \& Materials, Inc., Hampton, Virginia 23666, USA
}

\begin{abstract}
Using unstructured mesh CFD methods for Propulsion Airframe Aeroacoustics (PAA) analysis has the distinct advantage of precise and fast computational mesh generation for complex propulsion and airframe integration arrangements that include engine inlet, exhaust nozzles, pylon, wing, flaps, and flap deployment mechanical parts. However, accurate solution values of shear layer velocity, temperature and turbulence are extremely important for evaluating the usually small noise differentials of potential applications to commercial transport aircraft propulsion integration. This paper describes a set of calibration computations for an isolated separate flow bypass ratio five engine nozzle model and the same nozzle system with a pylon. These configurations have measured data along with prior CFD solutions and noise predictions using a proven structured mesh method, which can be used for comparison to the unstructured mesh solutions obtained in this investigation. This numerical investigation utilized the TetrUSS system that includes a Navier-Stokes solver, the associated unstructured mesh generation tools, post-processing utilities, plus some recently added enhancements to the system. New features necessary for this study include the addition of two equation turbulence models to the USM3D code, an $h$ refinement utility to enhance mesh density in the shear mixing region, and a flow adaptive mesh redistribution method. In addition, a computational procedure was developed to optimize both solution accuracy and mesh economy. Noise predictions were completed using an unstructured mesh version of the JeT3D code.
\end{abstract}

\section{Introduction}

With the intention to use CFD technology for the analysis of propulsion airframe integration effects on acoustics, it was demonstrated through a sequence of studies ${ }^{1-6}$ that high resolution CFD solutions using a Navier-Stokes solver with standard two equation k- $\varepsilon$ turbulence model could predict the mean flow structure of the jet exhaust flow correctly when compared to measured flow field data. In the case of a separate flow nozzle with an installed pylon, the CFD solutions provided detailed predictions of changes in the mean flow configuration between the core and the fan stream, the asymmetric turbulent kinetic energy distribution in the noise producing region of the exhaust flow, and a plausible explanation for the beneficial acoustic effects of pylon installation. CFD solutions were used as

\footnotetext{
${ }^{1}$ Senior Aerospace Engineer, Configuration Aerodynamics Branch, MS 499, NASA Langley Research Center, AIAA Associate Fellow

2 Aerospace Engineer, Configuration Aerodynamics Branch, MS 499, NASA Langley Research Center

${ }^{3}$ Senior Research Scientist, Eagle Aeronautics, Inc., 13 W. Mercury Blvd., Hampton, VA 23666, AIAA Member

${ }^{4}$ Senior Research Scientist, AS\&M, Inc., 107 Research Drive, Hampton, VA 23666, AIAA Member
} 
input data for the Jet3D code to predict noise and noise differentials between different configurations. This approach was also used to correlate noise with the aerodynamics induced by a variety of nozzle configurations and pylon installation effects. All these previous studies were conducted using the $\mathrm{PAB}^{3} \mathrm{D}^{1}$ code, a general purpose structured Navier-Stokes solver that contains many advanced turbulence models and boundary conditions suitable for propulsion airframe integration investigations. The computational mesh for these studies were generally in the range of 8 to 16 million cells. The time and effort for grid generation were nominally acceptable for configurations with moderate degrees of complexity. On the other hand, the topology for a separate flow nozzle system with an isolated pylon is relatively simple when compared with a typical commercial aircraft engine installation that would include also the wing, high lift flap and aileron systems, and other structural components that may interact with the engine exhaust flow. Alternately, laboratory installations for propulsion airframe aeroacoustics measurements would have support systems for subassemblies of engine and airframe components. A realistic CFD simulation would include many of these components in the computational domain. The time and cost to generate structured grids for these realistic configurations would be prohibitive in a typical research environment.

A logical alternative would be to use unstructured mesh computational methods. Currently available technology has shown that grid generation for complex aerodynamic configurations can be fast, efficient and accurate. On the other hand, shear flow mixing computation requires a two-equation turbulence model, and the unstructured NavierStokes codes available to the authors at the beginning of this study did not have a two-equation turbulence model implementation. In addition, there was no convenient procedure for unstructured grid generation to concentrate cell density in features such as a shear layers, wakes, or vortices in the volume of the computational domain. Even when these immediate difficulties were somehow resolved, it would be necessary to establish criteria for grid quality and procedures for computation such that accurate computations are converged, repeatable, and validated. The remainder of this paper will provide an outline for turbulence model implementation, unstructured mesh refinement methods, mesh enhancement by flow adaptation, grid convergence for aerodynamics and noise prediction. Two separate flow nozzle configurations are used in this study because these configurations are generic in nature, and both measured data and prior structured grid CFD solutions are available for comparison and validation purposes. Flow simulation results and noise predictions for these two selected configurations will be discussed in detail.

\section{Computational Method and Grid Generation}

The NASA Tetrahedral Unstructured Software System (TetrUSS) ${ }^{7}$ is a complete flow analysis system that has been widely used in industry and government since 1991. Its strength is derived from harnessing various component technologies into a user-friendly system to provide rapid, higher-order analysis and design capability to the applied aerodynamicist. TetrUSS consists of loosely integrated, user-friendly software that comprises a geometry setup tool GridTool $^{8}$, a tetrahedral grid generator VGRID ${ }^{9,10}$, a flow solver USM3D ${ }^{11,12}$, and post-processing grid repair, visualization, and data extraction utilities. The extensions addressed in this paper pertain to the USM3D flow solver and will be described below. In addition to the standard features of the TetrUSS system, this section will also describe several other computational methods and a noise prediction method used in this study.

\section{A. USM3D Flow Solver}

USM3D is a tetrahedral cell-centered, finite volume Euler and Navier-Stokes (N-S) flow solver. Inviscid flux quantities are computed across each cell face using Roe' $\mathrm{s}^{13}$ flux-difference splitting (FDS). Spatial discretization is accomplished by a novel reconstruction process ${ }^{14}$ based on an analytical formulation for computing solution gradients within tetrahedral cells. The solution is advanced to a steady state condition by an implicit backward-Euler time-stepping scheme ${ }^{15}$. Turbulence models in USM3D include the one equation Spalart-Allmaras (SA) model ${ }^{16}$, which can be coupled with a wall function to reduce the number of cells in the sublayer region of the boundary layer, the two-equation $\mathrm{k}-\varepsilon$ turbulence model $^{17}$ and the Menter SST two-equation model ${ }^{18}$. These turbulence models have undergone rigorous testing on propulsion afterbody flows by Hamid et al. ${ }^{19}$ The nonlinear algebraic Reynolds stress models (ARSM) by Girimaji ${ }^{20}$ and Shih et al. ${ }^{21}$ have also been installed in USM3D and are undergoing verification testing. The two-equation turbulence models were added to USM3D in the past few years mainly to meet the simulation requirements for propulsion airframe integration and high angle of attack flow conditions where shear layers, flow separation, and vortices are often the dominant components within the flow domain. Additional USM3D code features can be found in Frink et al. and Pandya et al. ${ }^{23-25}$ 


\section{B. Grid Generation and Refinement Tools}

Grid generation in this study follows the standard procedure in the TetrUSS system. The geometry is first prepared in GridTool, followed by the generation of surface mesh, viscous layer near solid surfaces, and tetrahedral cell generation in the Euler domain using VGRID. The next step is to enhance the cell density within a volume where the jet exhaust turbulent mixing layer will be located. This is accomplished by repeated h-refinement (spatial refinement) using a software package that is especially design and written for this study by Pao and by Hamid. The same h-refinement tool is used again to further enhance the grid quality in later stages of the flow solution development process.

\section{Adaptive Grid Enhancement}

Two flow adaptive methods are used in this study. The first one is a grid movement algorithm to adapt the mesh to flow gradients in the solution. In a r-refinement method developed by Campbell, a highly sensitive formulation based on the spring analogy adjusts the distance between neighboring nodes to equalize the gradient representation between nodes. Within each cycle of mesh adaptation to an intermediate flow solution, the grid node position adjustment is an iterative process. The number of iterations to attain better results is determined by the user. For the flow simulation requirements in this study, this mesh adaptive process would repeat somewhere between eight to twenty cycles, depending on the original mesh density. In this adaptive method, the number of mesh nodes and connectivity are not changed. Again, the number of solution iterations to reduce the flow solution residual between flow adaptation steps is optionally determined by the user according to the flow situation and mesh density. This adaptive process ends when flow features in the intermediate solutions settle into a steady state.

The second flow adaptive method is to refine the mesh in regions where the solution residual is the highest. The residual for the five primitive flow variables at each cell is written to a file at the end of computations. Cells targeted for refinement are selected if a weighted and normalized value of the residual falls within a user determined range. The mesh is then selectively refined using the h-refinement tool according to a list of the identified cells, and computation is continued on the refined mesh.

\section{Solution Interpolation}

Experience from structured mesh shear flow computations indicated that grid sequencing would help the proper development of turbulence levels from the uniform initial conditions in the computational domain containing boundary layers and shear layers. While grid sequencing is natural and easily managed in a structured mesh, it is not the same in unstructured mesh computations because there is no explicit sequence in the unstructured mesh itself. For a computational process that continues from one mesh to another in the course of a single flow simulation, a solution interpolation utility is very useful. A flow solution interpolation method based on the octree algorithm was design and coded by Massey and it is used extensively in this study to copy the flow solution from a coarser mesh to a finer mesh, or sometimes just to another mesh of better quality.

\section{E. The Jet3D Noise Prediction Code}

The Jet3D software ${ }^{4,26,27}$ was used for noise prediction and jet noise source diagnostics in this study. Jet3D is based on a modern implementation of Lighthill's Acoustic Analogy (LAA) with anisotropic Reynolds stress modeling, and has been developed to handle complex three-dimensional turbulent flows and installed jet configurations. As discussed by Hunter and Thomas ${ }^{2}$, previous Jet3D SPL predictions were in good agreement with experimental noise measurements in the inlet arc, for configurations used in this study. Jet arc predictions were good up to about $121^{\circ}$ inlet angle, beyond which Jet3D under predicted low frequency SPL levels (due to inherent limitations in the implementation of LAA used in Jet3D). Jet3D predicted full-scale-equivalent EPNL within the standard deviation band of measured data. For the current study, Jet3D was modified to handle unstructured CFD data from USM3D. Minimal changes were required to compute noise on tetrahedral cells, because of the finite volume formulation of Jet3D (originally developed for hexahedral cells in structured CFD grids). 


\section{Computational Procedures of Separate Flow Nozzles with and without a Pylon}

Two configurations were selected for this evaluation/validation study of using an unstructured mesh for flow simulation and noise prediction. The first configuration, CF1, was a fan and core separate flow round nozzle with a bypass ratio (BPR) of 5 . Although the exhaust flow was expected to be axisymmetric, the mesh was made for half of the nozzle bounded by a vertical plane of symmetry. The second configuration, CF6, was the same nozzle system with a pylon having a shape and position similar to a large commercial aircraft installation. The flow conditions for the fan stream, the core stream, and the ambient atmosphere are nominally those for airplane takeoff simulations. Measurements and structured mesh flow simulations using these identical configurations and flow conditions were previously reported in Massey et al. ${ }^{5}$ and Thomas et al. ${ }^{6}$. The flow conditions are given in Table I.

Table I: Ambient and engine exhaust flow conditions

\begin{tabular}{l|c|c|c}
\hline & Total Pressure, psi & Total Temperature, $\mathbf{R}$ & Mach Number \\
\hline Acoustic Wind Tunnel & 14.70 & 530 & 0.280 \\
\hline Fan Stream & 24.36 & 647 & 0.931 \\
\hline Core Stream & 21.72 & 1491 & 0.823 \\
\hline
\end{tabular}

Several grids were made for each of these two configurations. A grid convergence study was performed using CF1. Four levels of mesh were made for this purpose: coarse, medium, fine, and superfine. Two levels of mesh were made for CF6: fine and superfine. In addition to this group of grids, two initial grids, one for each configuration, containing only high quality mesh for the nozzle interior and near the pylon surfaces were generated for the purpose of rapid development of boundary layer flows next to the solid surfaces.

The coarse, medium, and fine meshes were generated such that the grid quality and relative cell size distribution throughout the flow domain were similar. This was accomplished by utilizing the "ifact" parameter in VGRID as a control for the Euler cell size in each mesh. The relative ratio of cell sizes in the coarse, medium, and fine grids are approximately $1.4,1.0$, and 0.7 , respectively. These grids then went through an identical four-step h-refinement process to create a working mesh for computations. The total cell count ratio between mesh levels was approximately a factor of 2. The superfine mesh was constructed from the fine mesh by h-refinement of selected cells in the shear layer where the residual values are the highest. The total cell count for this refinement increased again by a factor of two. This selective refinement process created a similarity between these finest grid levels that is somewhat different from the similarity between the lower three mesh levels. It is worth noting that in all these meshes, cell density in the jet mixing domain maintained a very slow linear cell size expansion along the jet plume streamwise direction. This nearly constant cell size in a local region is necessary for better turbulent flow development, an experience learned from many years of structured mesh jet exhaust flow simulations. The rule of thumb is that a minimum of 20 cells per jet diameter in the stream-wise direction should be maintained in a fine grid for the development of a good quality flow solution. Mesh size details are given in Table II.

The CF1 and CF6 flow simulations used the RANS solver in USM3D and the standard k- $\varepsilon$ turbulence model (according to the Jones-Launder formulation) with a linear Reynolds stress model. A converged viscous solution was produced for each configuration using an initial mesh that provided fine details in only the nozzle and pylon neighborhood with minimal enhancements in the jet exhaust flow domain. It took approximately 10,000 to 12,000 iterations to establish the velocity and temperature distributions in the nozzle boundary layer and the internal flow paths. For the CF1 case, this solution was interpolated to the coarse, medium, and fine mesh as their respective starting solution. For the CF6 case, the initial nozzle solution was interpolated to the fine mesh as its starting solution. For each of these meshes, it took approximately 4000 iterations for convergence to a solution where the residual would level off to a constant value. 
Table II: Grid sizes at various density levels for CF1 and CF6

\begin{tabular}{l|r|r|r|r}
\hline Grid Name & Nodes & Total Cells & \multicolumn{1}{c|}{ Viscous Cells } & \multicolumn{1}{c}{ Inviscid Cells } \\
\hline CF1 Coarse & 592,626 & $3,363,524$ & 837,212 & $2,526,312$ \\
\hline CF1 Medium & $1,388,147$ & $7,991,863$ & $1,556,778$ & $6,435,085$ \\
\hline CF1 Fine & $2,527,402$ & $14,658,519$ & $2,323,555$ & $12,334,964$ \\
\hline CF1 Super Fine & $5,245,046$ & $30,659,315$ & $2,418,134$ & $28,241,181$ \\
\hline CF6 Fine & $3,297,696$ & $19,267,474$ & $3,311,687$ & $15,955,787$ \\
\hline CF6 Super Fine & $6,949,309$ & $40,821,251$ & $3,428,750$ & $37,392,501$ \\
\hline
\end{tabular}

At this stage, regardless of the mesh density level, the length of the total temperature core length fell far short of the expected core length value according to either experimental measurements or previous structured mesh computations using PAB3D. Two primary factors led to this rapid mixing in numerical simulation. First, the height of the tetrahedral cells were too large relative to the shear layer such that different layers of the shear flow would enter a single cell, and each flow variable was then averaged to a single cell center value. Second, the typical Euler cell in the mesh is isotropic and therefore not efficient in supporting the shear flow gradient that has by nature a directional preference. During preliminary stages of this study, it was discovered that cell densities up to four times of the current fine mesh did not entirely solve the problem of insufficient shear flow representation. Instead of attacking the problem by seeking even high mesh density, mesh enhancement by adapting to flow was pursued instead. The Campbell adaptive mesh node positioning method had the distinct advantage of multiple adaptive cycles within one run without user intervention. In this study, a 250 solution-iteration step was conservatively chosen for reducing the solution residual between mesh adaptation cycles. Somewhere between 8 and 20 mesh adaptive cycles were used for various solutions to establish an appropriate cell distribution in the shear layers in the computational domain. On account of the flow topology and the nature of the spring-analogy mesh movement algorithm, the shear layer's demand for high density resulted in cell depletion near the jet flow axis. The situation was remedied quite easily by a single step of h-refinement in the depleted region after the adaptive cycles were completed. A converged solution was then obtained from this adapted and repaired mesh. In order to convincingly establish grid convergence of the aerodynamic solutions and to provide a measure of grid sensitivity for noise prediction using Jet3D, a super-fine mesh was produced for CF1 and CF6. A different strategy was used to further enhance the grid. An algorithm designed by Hamid selected cells with the highest values of residual error and refinined these cells through h-refinement. The refined mesh would therefore support a better flow resolution and quality of the predicted shear layer.

\section{Discussion of USM3D Flow Simulation Results}

Since this is a first study of separate flow engine exhaust simulation using unstructured mesh and the USM3D code, the simpler CF1 configuration served as the basis for demonstrating solution convergence behavior and grid convergence of the solution. As mentioned in the previous section, the solution development process took several steps from start to finish. Figure 1 shows the convergence history for the CF1 fine mesh case. Using a generic mesh that contained a fine mesh in the vicinity of the nozzle assembly, an initial solution was developed in 10000 iterations. At that point, h-refinement was use to bring the mesh to fine grid level by enhancing the mesh density throughout the exhaust mixing flow domain such that a minimum of 30 cells per diameter was achieved from the nozzle exit to $\mathrm{X} / \mathrm{D}=30$. The initial generic solution was interpolated to the new mesh and developed to more than four orders of magnitude of residual reduction. The flow adaptive process started at this point and concluded after 14 cycles of flow adaptation. The solution was again developed for several thousand iterations. It was noted that solution residual reduction stopped short of four orders of magnitude. Two steps of remedy were attempted. First, the cell density near the flow centerline was enhanced by one step of h-refinement in that region. While the residual reduction situation did not improve, it was discovered that the mesh contained a single nearly collapsed cell. The mesh was quickly repaired using the PostGrid utility and the solution was interpolated to the new mesh. The solution development proceeded smoothly to completion.

Figure 2 shows a comparison of the centerline total temperature between previously published PAB3D solutions (with and without temperature corrected turbulence closure), USM3D solutions (without temperature corrected 
turbulence closure), and a very sparse set of measured data for the same configuration and flow conditions. The USM3D solutions are shown at four different grid density levels. The difference between the medium grid solution and the fine grid solution is small. The fine and super-fine mesh solutions are practically on top of each other: the fine mesh solution is marked with symbols to indicate its existence in Figure 2. Figure 3 shows the adapted grid cross section at $\mathrm{X} / \mathrm{D}=2$ for $\mathrm{CF} 1$ at three grid levels. The mesh configuration started from a more or less uniform distribution at the beginning of the adaptive process. The adaptive process was very efficient in pulling the cells to where they were needed in the shear layer.

Contours of normalized total temperature are shown in Figure 4 for $C F 1$ at $\mathrm{X} / \mathrm{D}=2,5,10,17$. Comparison between experimental data, PAB3D and USM3D predictions are generally in good agreement. Figure 2 and Figure 4 indicate that USM3D predictions show less mixing than PAB3D. At all X/D stations, the high temperature core of the USM3D solution had larger diameters than those predicted by PAB3D. The USM3D mixed centerline temperature at $\mathrm{X} / \mathrm{D}=17$ was predicted $16 \%$ higher than the $\mathrm{PAB} 3 \mathrm{D}$ solution.

Figure 5 shows the convergence history for CF6. In this case, one collapsed cell was also found at the end of the flow adaptive mesh improvement process. The grid was repaired before continuing the flow solution iterations. Contours of normalized total temperature are shown in Figure 6 for $\mathrm{CF} 6$ at $\mathrm{X} / \mathrm{D}=2,5,10,17$. The total temperature cross section has much better similarity between the USM3D and the PAB3D solutions. Differences in details can still be noticed especially at $\mathrm{X} / \mathrm{D}=5$ and $\mathrm{X} / \mathrm{D}=10$.

Figure 7 shows total temperature predictions by USM3D in the vertical symmetry plane for CF1 and CF6. Examination of these plots shows a very basic characteristic of the jet pylon interaction ${ }^{26}$. The pylon induces the core stream to move upward and the resulting core flow cross section takes on a cardioid like shape at $\mathrm{X} / \mathrm{D}=5$ but reverts back towards a circular shape farther down-steam.

\section{Noise Prediction Using JET3D}

Sound pressure level (SPL) predictions from Jet3D are shown in figures 8 and 9, for CF1 and CF6 respectively. Both plots include PAB3D results with and without temperature corrected turbulence closure; the former were published by Hunter and Thomas ${ }^{4}$ while the latter are included here to compare with USM3D results without temperature correction. Experimental data are also taken from Hunter and Thomas ${ }^{4}$. In figure 8, the multiple grid adaptation refinements used with USM3D show a progressive improvement in noise prediction but stall at the superfine case. While low frequency noise in the USM3D-based predictions is in line with PAB3D-based predictions and experimental data, USM3D high frequency noise is significantly (5-15dB) lower than the other two. Similar results are seen in figure 9 for CF6.

To diagnose this high-frequency noise deficiency, Jet3D noise source maps were generated for CF1, using both PAB3D and USM3D (superfine) input data (figures 10 and 11, respectively). These noise maps, which show meansquare acoustic pressure per unit volume in the $50 \mathrm{kHZ}$ frequency band, are overlaid on the computational mesh in each case. Both maps show similar source patterns focused around the fan nozzle lip, but the levels of noise source density are an order of magnitude lower in the USM3D case. Since turbulent kinetic energy (TKE) is an underlying driver for noise, that quantity is plotted in figures 12 and 13. In this case, the TKE in the range of the $50 \mathrm{kHz}$ noise sources is 1.5 to 2 times weaker in the USM3D solution than the PAB3D solution.

Additional diagnostics, not shown here, indicated that there were similar boundary layer turbulence levels inside the fan nozzle from both PAB3D and USM3D, so it appears the turbulence levels "fizzled out" as flow left the nozzle, then slowly began to grow again. This suspicion was confirmed by a highly magnified view of TKE levels in the nozzle lip region as shown in figures 14 and 15. Based on these images, it appears that the unstructured mesh had an unfavorable topology and was too coarse to fully support the transition of turbulence from the boundary layer to the free shear layer. In the case of structured grids, this is rarely an issue because boundary layer resolving mesh is fanned out into the shear layer, providing over-abundant resolution and smooth blending in the nozzle lip region. In contrast, unstructured grid generation methods have distinct viscous and inviscid mesh regions, and special care must be taken to obtain adequate blending, transition, and resolution around corners and at trailing edges. The adverse impact of grid topology and resolution on turbulence and noise prediction underscores the critical importance of careful grid generation in critical regions such as nozzle lips. 


\section{Concluding Remarks}

This study has demonstrated that the efficient TetrUSS CFD system can be extended to PAA applications by establishing a methodology of using the USM3D flow solver, the Jet3D noise prediction code, grid generation tools, and innovative process management. A few utilities were added to the repertoire of TetrUSS for these new applications that would potentially benefit the analysis and design of propulsion related components and propulsionairframe integration. Specifically, this study found that the USM3D solutions of shear layers in separate flow engine exhaust are comparable to those previously obtained by using PAB3D for identical configurations and flow conditions. However, Jet3D noise predictions showed that further grid refinement and flow solution development is needed in high-frequency regions of nozzle shear layers, downstream of nozzle exit lips. As the main objective of this validation study, detailed turbulent flow simulation and the associated noise prediction show that the PAA applications can indeed take advantage of the efficiency and flexibility of the unstructured mesh CFD technology. Further development of aerodynamic simulation and noise prediction procedures and applications to high priority PAA projects will continue at NASA Langley Research Center.

\section{References}

[1] Abdol-Hamid, K.S., Pao, S.P., Hunter, C.A., Deere, K.A., Massey, S.J., and Elmiligue, A.A., "PAB3D: Its History in the Use of Turbulence Models in the Simulation of Jet and Nozzle Flows", AIAA-2006-489, 44th AIAA Aerospace Sciences Meeting and Exhibit, Reno, Nevada, Jan. 9-12, 2006.

[2] Abdol-Hamid, K.S., Elmiligue, A.A., "Numerical Study of High-Temperature Jet Flow Using RANS/LES and PANS Formulations", AIAA-2005-5092,23rd AIAA Applied Aerodynamics Conference, Toronto, Ontario, June 6-9, 2005

[3] Abdol-Hamid, K., Pao, S. P., Massey, S.J., and Elmiligui, A.A., "Temperature Corrected Turbulence Model for High Temperature Jet Flow”, J. Fluids Engineering, Vol. 126, pp. 844-850, 2004

[4] Hunter, C. A., and Thomas, R.H., "Development of a Jet Noise Prediction Method for Installed Jet Configurations", AIAA2003-3169, 9th AIAA/CEAS Aeroacoustics Conference and Exhibit, Hilton Head, South Carolina, May 12-14, 2003

[5] Massey, S.J., Thomas, R.H., Abdol-Hamid, K.S., and Elmiligue, A.A., "Computational and Experimental Flowfield Analyses of Separate Flow Chevron Nozzles and Pylon Interaction", AIAA-2003-3212, 9th AIAA/CEAS Aeroacoustics Conference and Exhibit, Hilton Head, South Carolina, May 12-14, 2003

[6] Thomas, Russell H., Kinzie, Kevin W., and Pao, S. Paul, "Computational analysis of a pylon-chevron core nozzle interaction”, AIAA-2001-2185 AIAA/CEAS Aeroacoustics Conference and Exhibit, Maastricht, Netherlands, May 28-30, 2001.

[7] Frink, N.T., Pirzadeh, S.Z., Parikh, P.C., and Pandya, M.J., "The NASA Tetrahedral Unstructured Software System (TetrUSS)," The Aeronautical Journal, Vol.104, No. 1040, October 2000, pp. 491-499.

[8] Samareh, J., "GridTool: A surface modeling and grid generation tool," Proceedings of the Workshop on Surface Modeling, Grid Generation, and Related Issues in CFD Solutions," NASA CP-3291, 9-11 May, 1995.

[9] Pirzadeh, S., "Structured background grids for generation of unstructured grids by advancing front method," AIAA Journal, Vol. 31, No. 2, February 1993, pp. 257-265.

[10] Pirzadeh, S., "Unstructured viscous grid generation by advancing-layers method," AIAA Journal, Vol. 32, No. 8, August 1994, pp. 1735-1737.

[11] Frink, N. T., "Upwind scheme for solving the Euler equations on unstructured tetrahedral meshes," AIAA Journal, Vol., No. 1, January 1992, pp. 70-77.

[12] Frink, N. T., "Tetrahedral unstructured Navier-Stokes method for turbulent flows," AIAA Journal, Vol. 36, No. 11, November 1998, pp. 1975-1982.

[13] Roe, P., "Characteristic based schemes for the Euler equations," Annual Review of Fluid Mechanics, Vol. 18, 1986, pp. 337365.

[14] Frink, N. T., "Recent progress toward a three-dimensional unstructured Navier-Stokes flow solver," AIAA 94-0061, 32 ${ }^{\text {nd }}$ Aerospace Sciences Meeting and Exhibit, Reno, NV, January 1994.

[15] Anderson, W.; and Bonhaus D., "An implicit upwind algorithm for computing turbulent flows on unstructured grids,", Computers Fluids, Vol. 23, No. 1, 1994, pp. 1-21.

[16] Spalart P., and Allmaras S. A., "One-equation turbulence model for aerodynamic flows," AIAA Paper 92-0439, 30 th Aerospace Sciences Meeting, Reno, NV, January 1992.

[17] Jones,W. P., and Launder, B. E., "The Prediction of Laminarization With a Two-Equation Model of Turbulence," Int. J. Heat \& Mass Transf., vol. 15, no. 2, Feb. 1972, pp. 301-314. 
[18] Menter, F.R., "Improved Two-Equation k-omega Turbulence Models for Aerodynamic Flows", NASA TM-103975, October 1992.

[19] Abdol-Hamid, K. S. Frink, N. T., Deere, K. A., and Pandya, M.J., "Propulsion Simulations Using Advanced Turbulence Models with the Unstructured-Grid CFD Tool, TetrUSS," AIAA Paper 2004-0714, 42 ${ }^{\text {nd }}$ AIAA Aerospace Sciences Meeting and Exhibit, Reno, NV, January 2004.

[20] Girimaji, S.S., "Fully-Explicit and Self-Consistent Algebraic Reynolds Stress Model," ICAS Report 95-82, 1995.

[21] Shih, T-H., Zhu, J., and Lumley, J.L., “A New Reynolds Stress Algebraic Model,” NASA TM-166614, ICOMP 94-8, 1994.

[22] Abdol-Hamid, K. S. Frink, N. T., Deere, K. A., and Pandya, M.J., "Propulsion Simulations Using Advanced Turbulence Models with the Unstructured-Grid CFD Tool, TetrUSS," AIAA Paper 2004-0714, $42^{\text {nd }}$ AIAA Aerospace Sciences Meeting and Exhibit, Reno, NV, January 2004.

[23] Frink, N.T., Bonhaus, D.L., Vatsa, V.N., Bauer, S.X.S., Tinetti, A.F., “A Boundary Condition for Simulation of Flow Over Porous Surfaces,” Journal of Aircraft, vol. 40, no. 4, July-August 2003, pp. 692-698.

[24] Pandya, M.J., Frink, N.T., Abdol-Hamid, K.S., and Chung, J.J., "Recent Enhancements to USM3D Unstructured Flow Solver for Unsteady Flows," AIAA Paper 2004-5201, $22^{\text {nd }}$ Applied Aerodynamics Conference and Exhibit, Providence, RI, August 16-19 2004.

[25] Pandya, M.J., Frink, N.T., and Noack, R.W., "Overset-Grid Moving Body Capability in the USM3D Unstructured Flow Solver," AIAA Paper 2005-5118, $17^{\text {th }}$ AIAA computational Fluid Dynamics Conference, Toronto, Ontario, June 6-9 2005.

[26] Hunter, C.A., Thomas, R.H., Abdol-Hamid, K.S., Pao, S.P., Elmiligui, A.A., and Massey, S.J., "Computational Analysis of the Flow and Acoustic Effects of Jet-Pylon Interaction". AIAA-2005-3083, 11th AIAA/CEAS Aeroacoustics Conference, Monterey, CA, May 23-25, 2005

[27] Hunter, C. “An Approximate Jet Noise Prediction Method Based on Reynolds-Averaged Navier-Stokes Computational Fluid Dynamics Simulation.” D.Sc. Dissertation, The George Washington University, January, 2002.

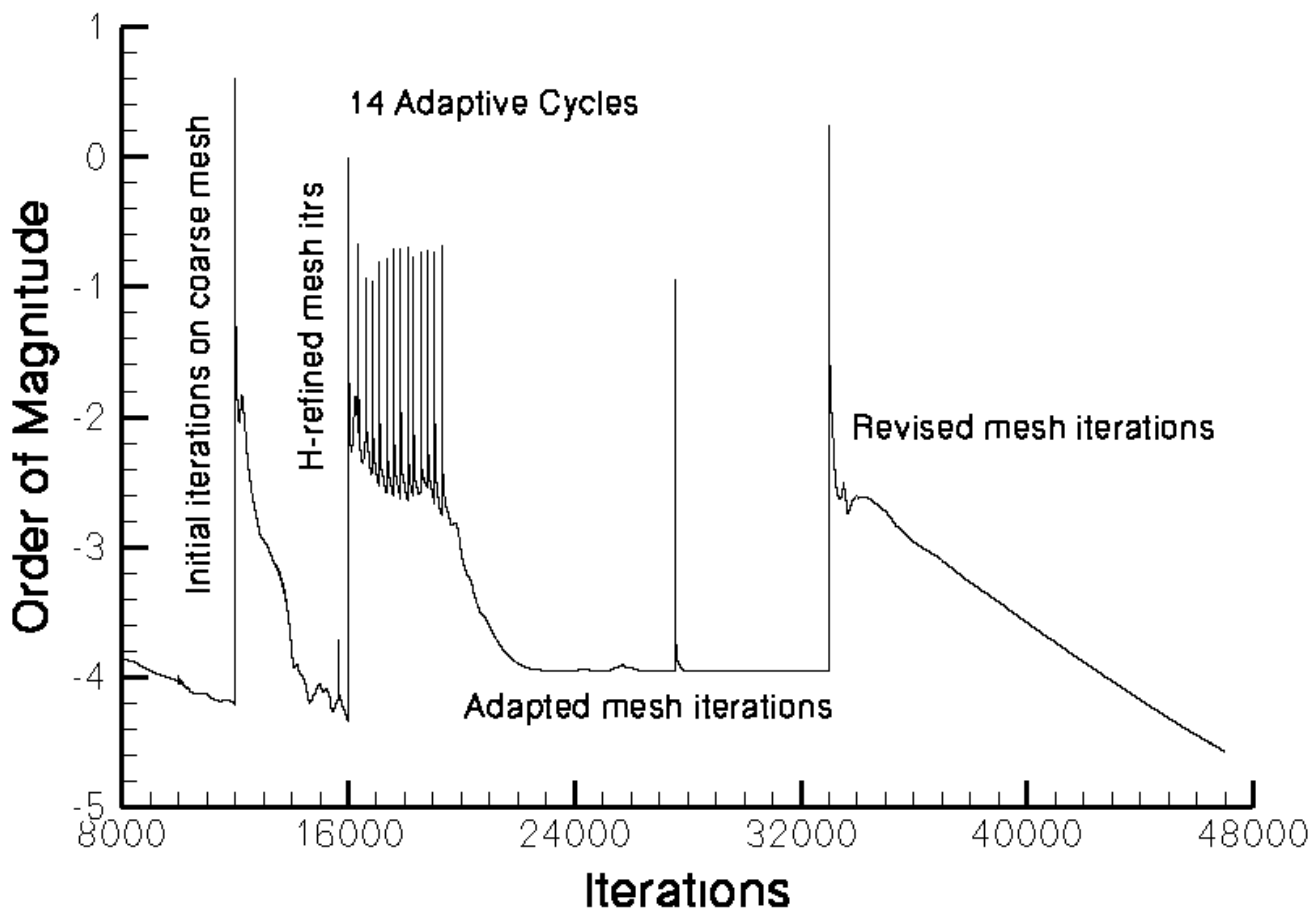

Figure 1: Convergence history for CF1 fine mesh 


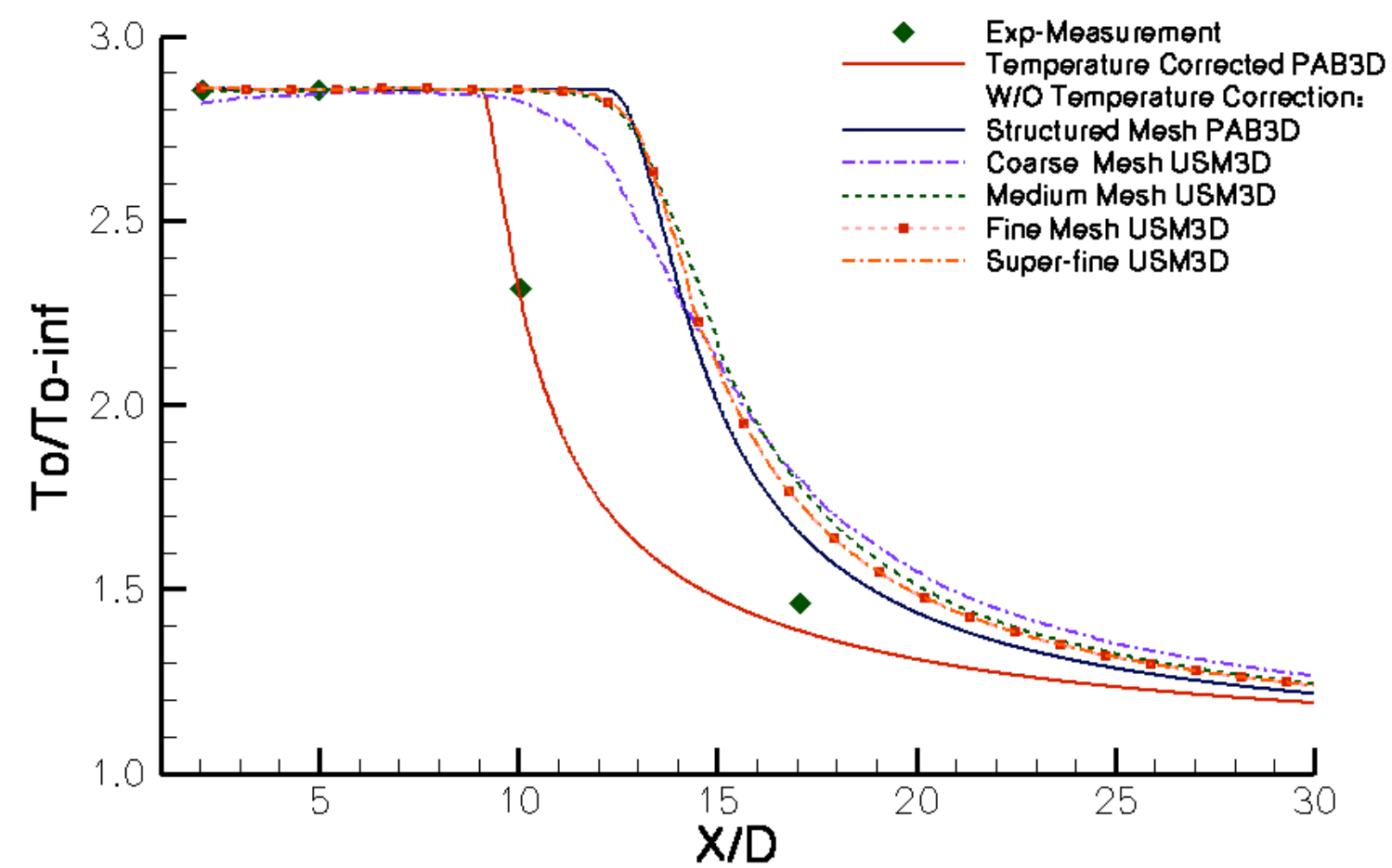

Figure 2: Comparisons of CF1 centerline normalized total temperature for USM3D solutions at four grid levels, previous PAB3D solutions, and measured data
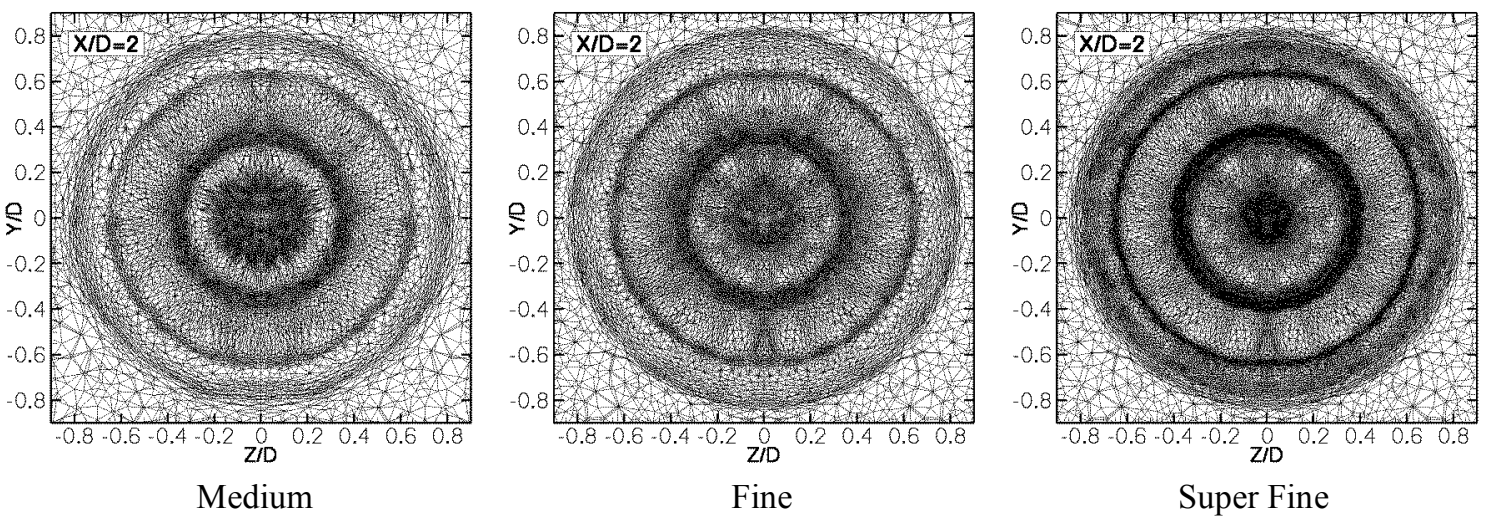

Figure 3: $\mathrm{CF} 1$ grid cross sections at $\mathrm{X} / \mathrm{D}=2$

(Cross cuts show mesh interpolated to slicing plane, not actual computational mesh) 

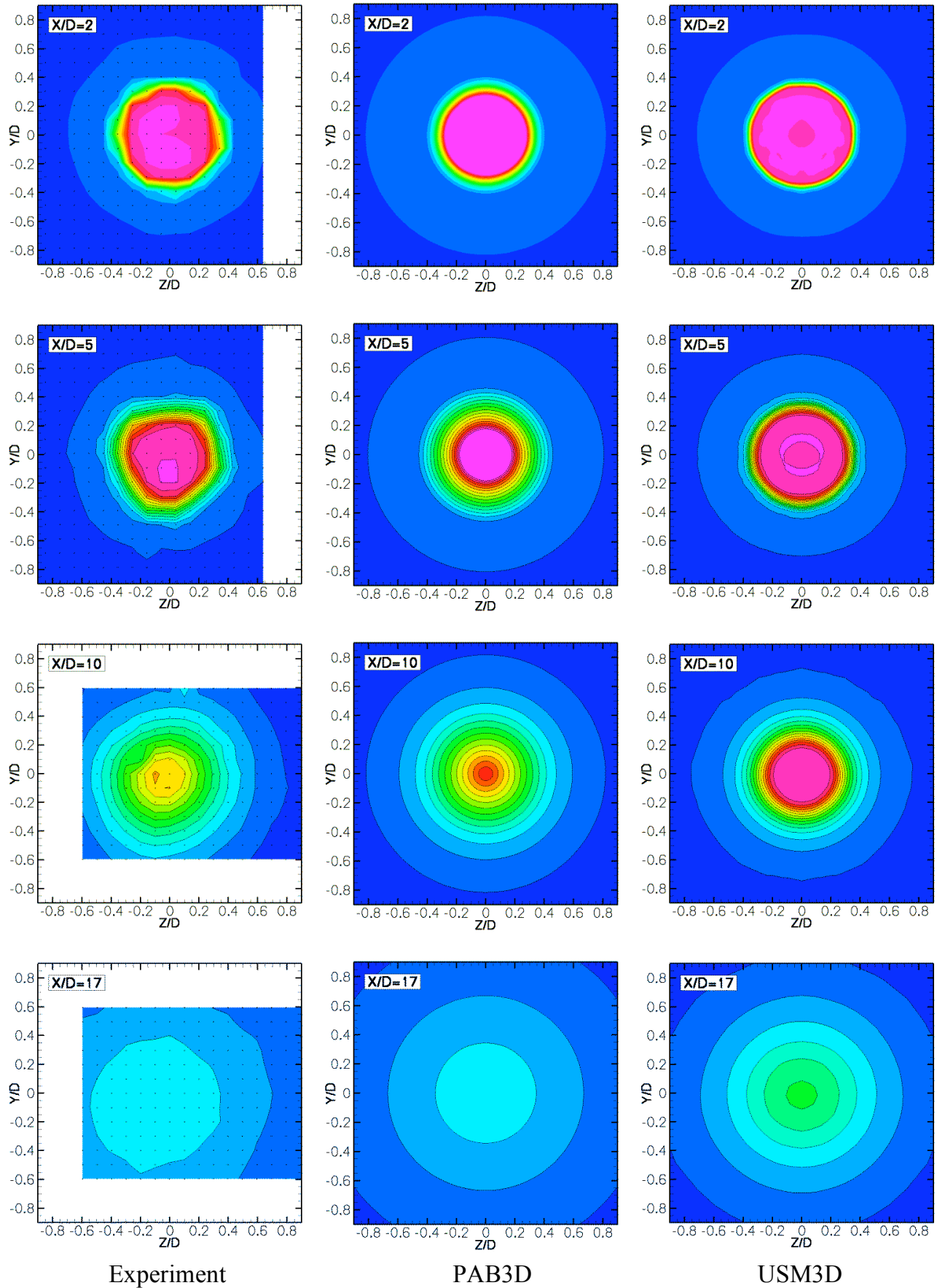

$\mathrm{T}_{\mathrm{o}} / \mathrm{T}_{\mathrm{o}, \text { core }}$

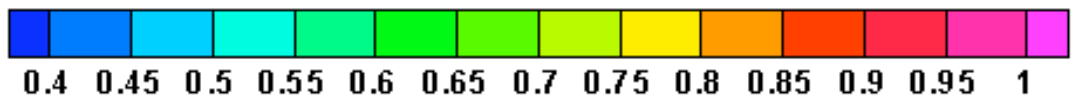

Figure 4: CF1 Round Nozzle - normalized total temperature cross sections at $x / D=2,5,10,17$ 


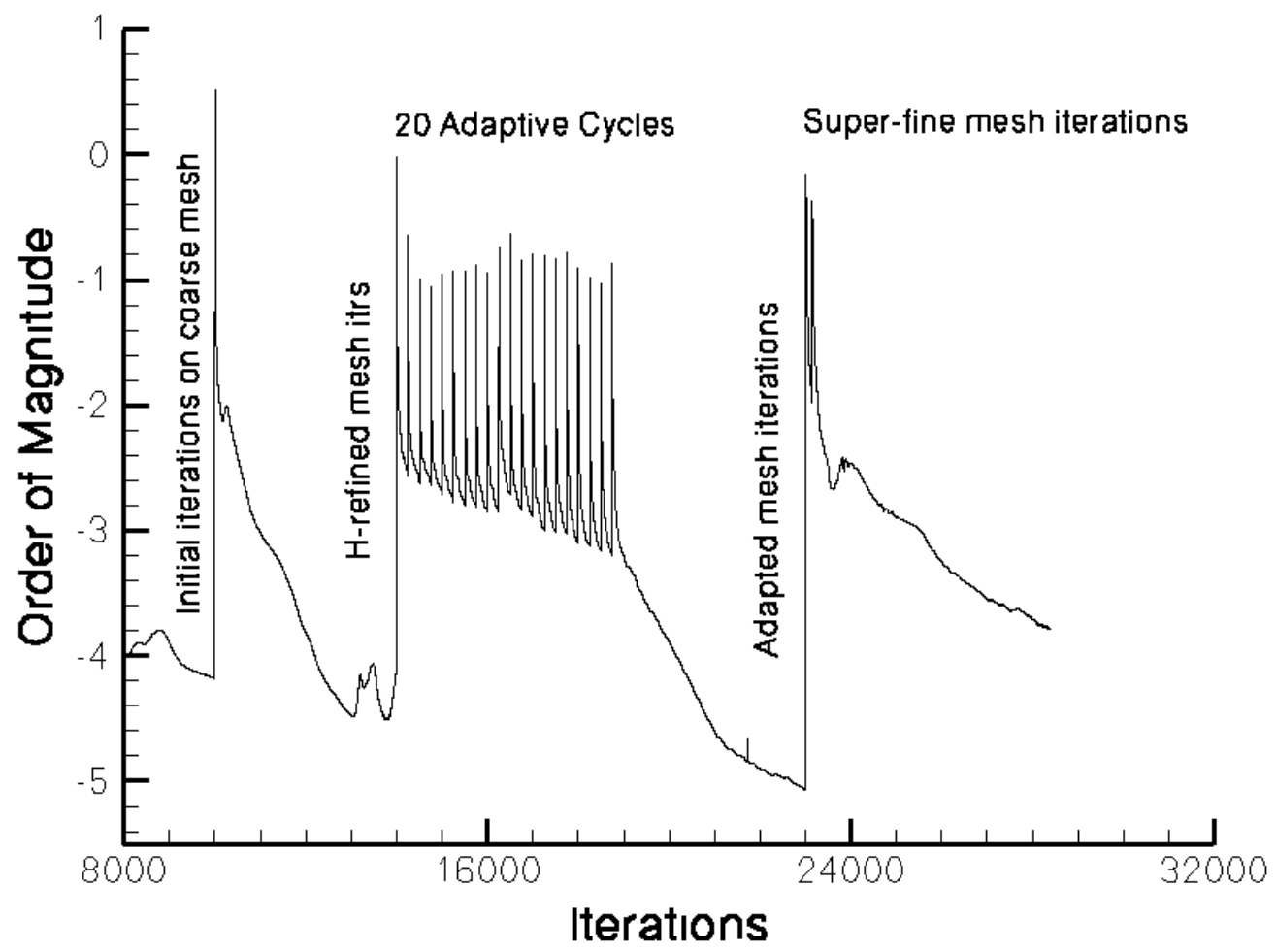

Figure 5: Convergence history for CF6 fine and superfine meshes

PAB3D predictions
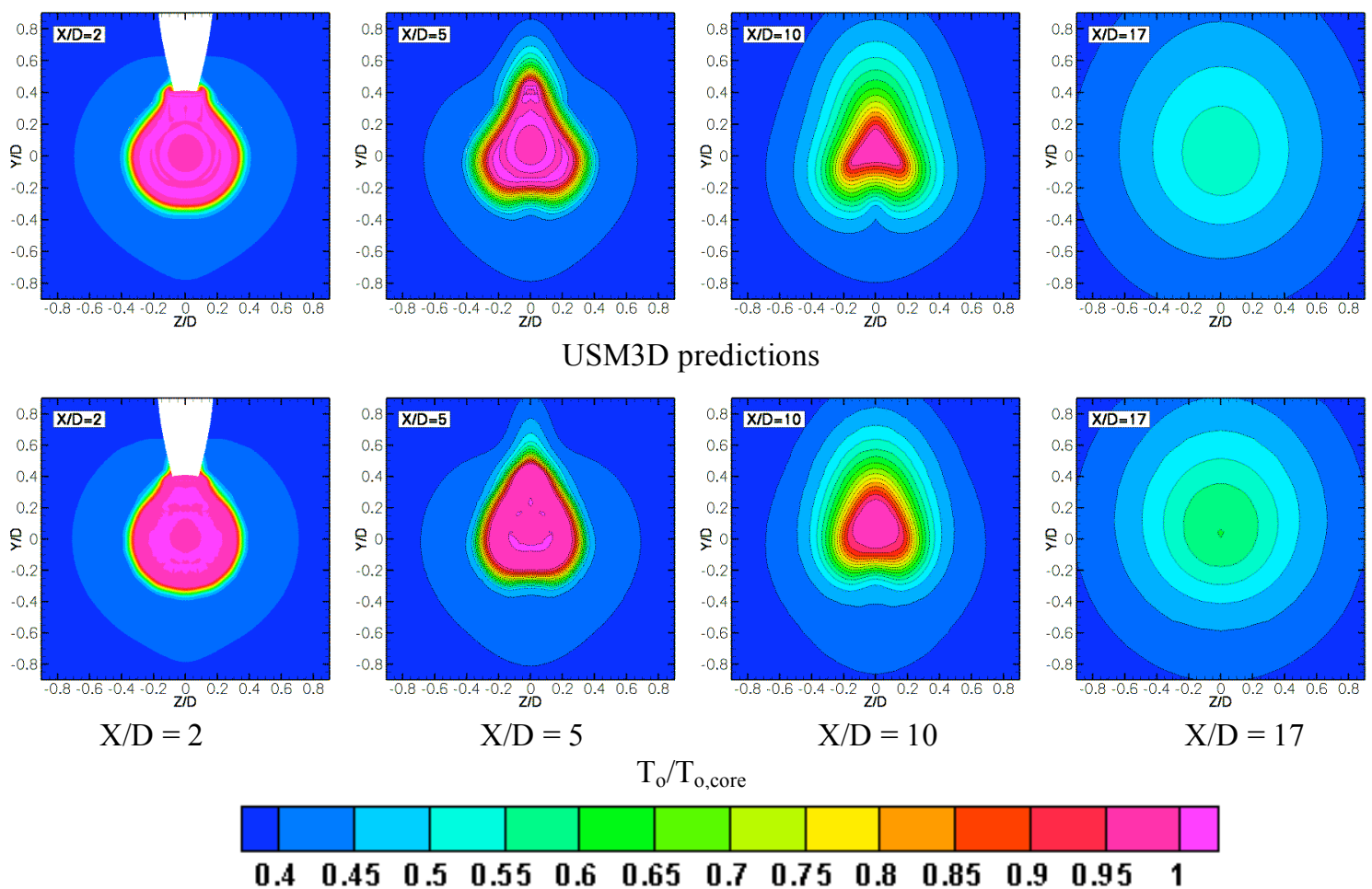

Figure 6: CF6 Pylon Nozzle - normalized total temperature cross sections at $X / D=2,5,10,17$ 

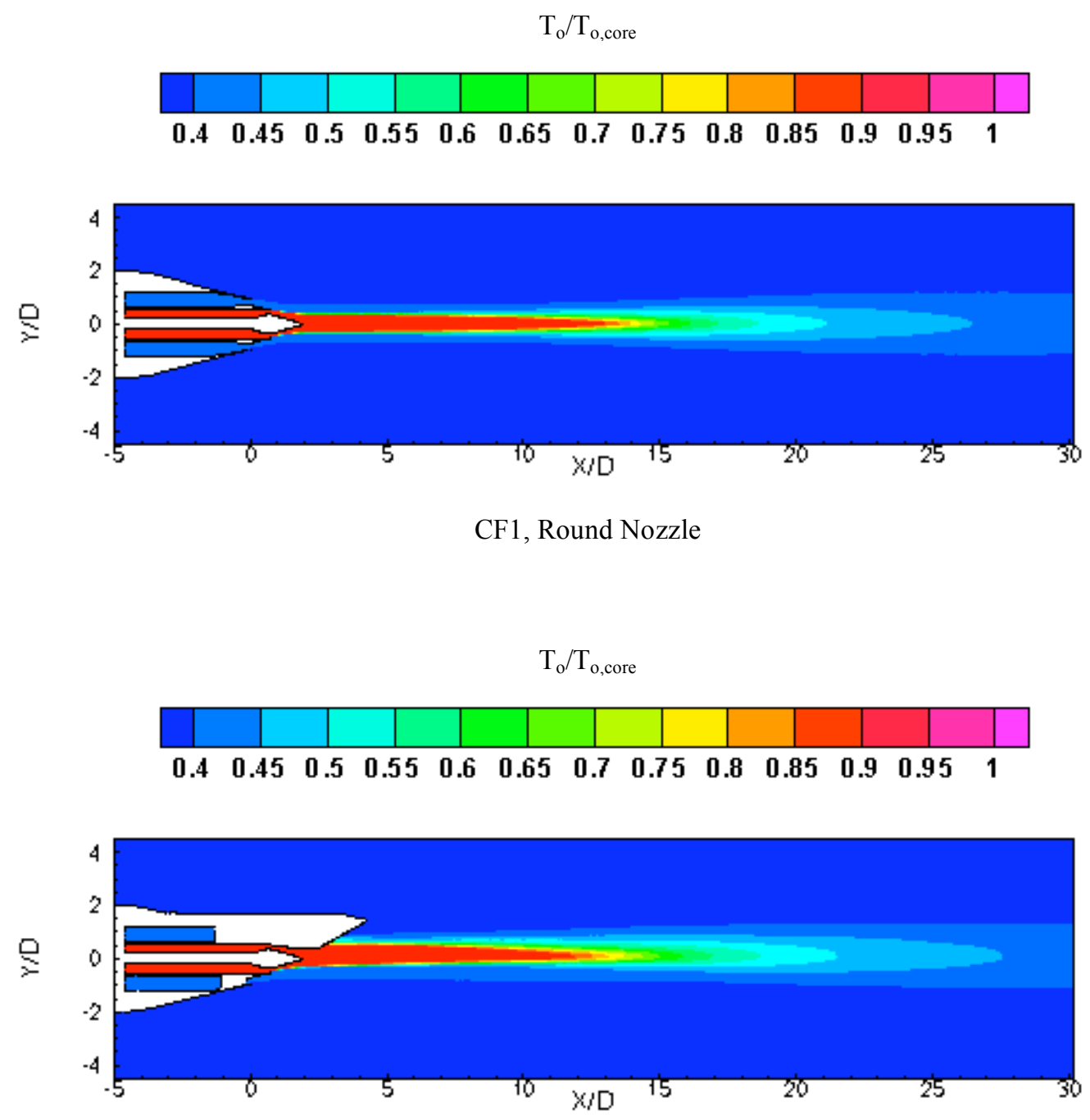

CF6, Pylon and Nozzle

Figure 7: Normalized total temperature on symmetry plane for CF1 and CF6 


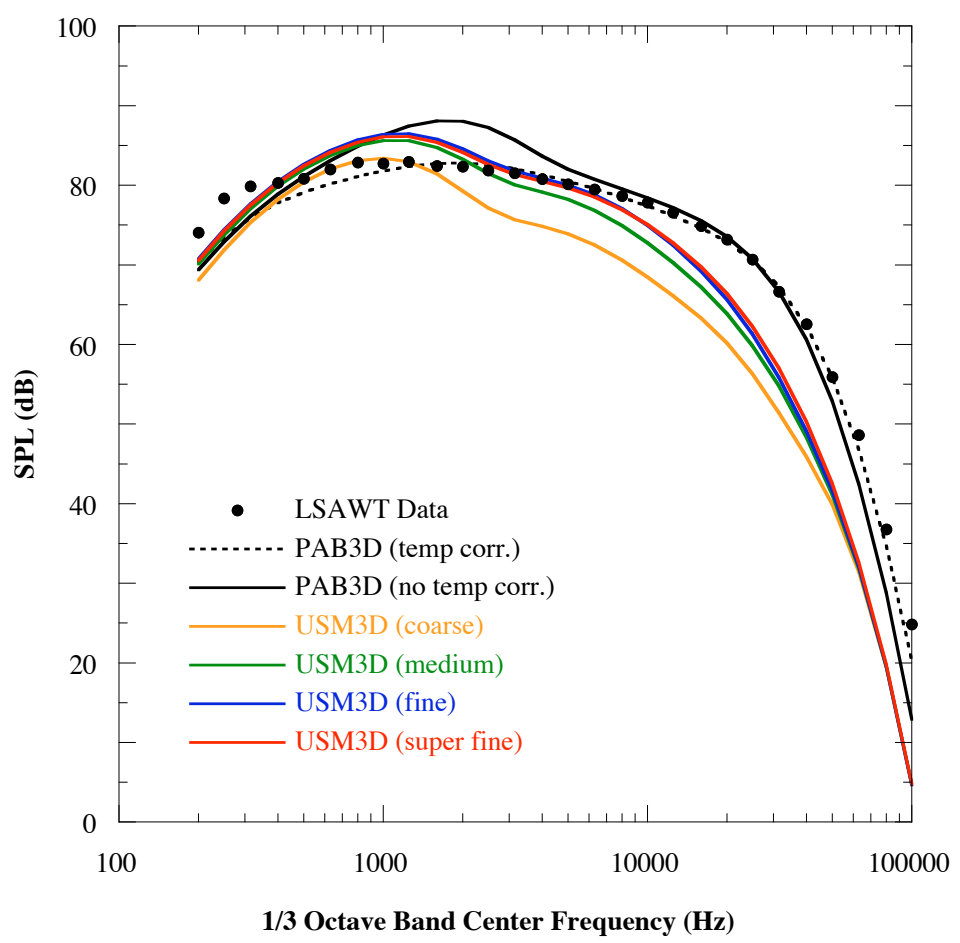

Figure 8: Sound Pressure Level (SPL) Predictions for CF1

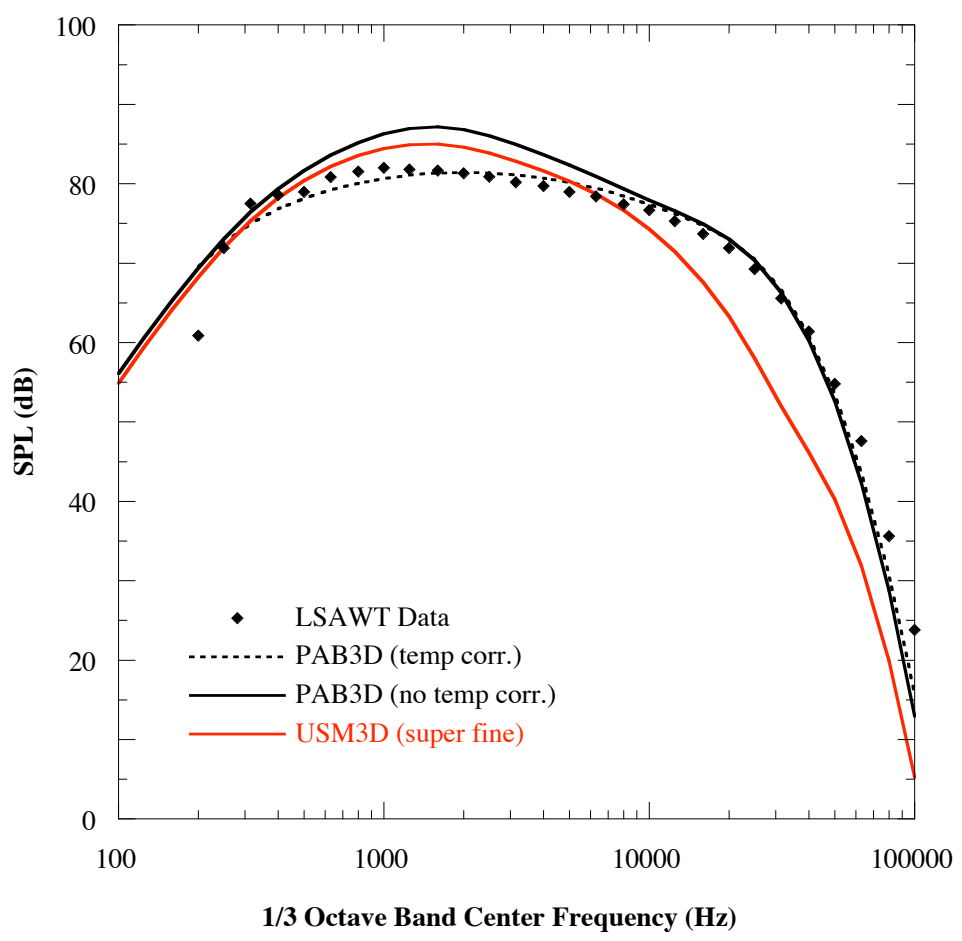

Figure 9: SPL Predictions for CF6 


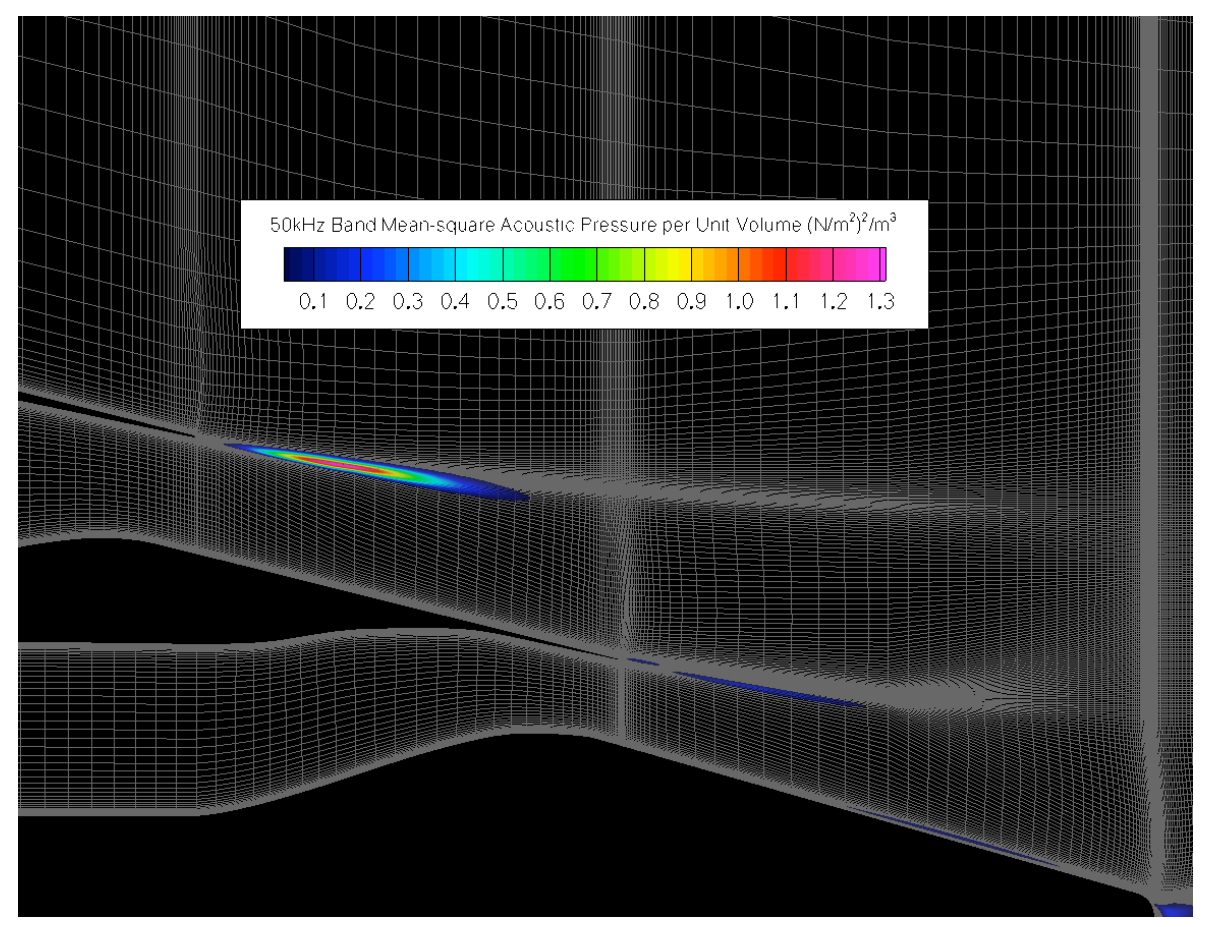

Figure 10: CF1 noise source map, $50 \mathrm{kHz} 1 / 3$ octave band, PAB3D input data and structured mesh

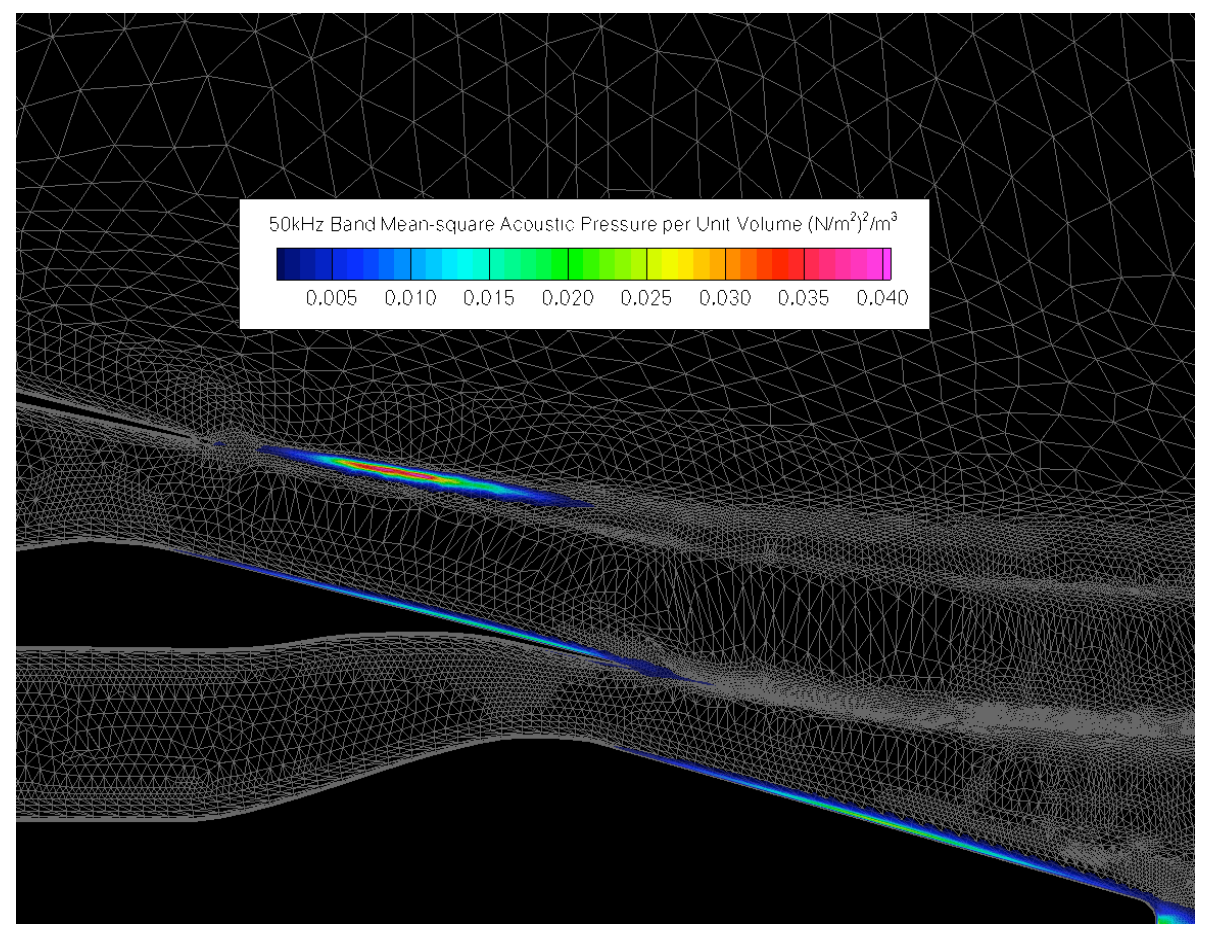

Figure 11: CF1 noise source map, $50 \mathrm{kHz} 1 / 3$-octave band, USM3D input data and superfine adapted unstructured mesh 


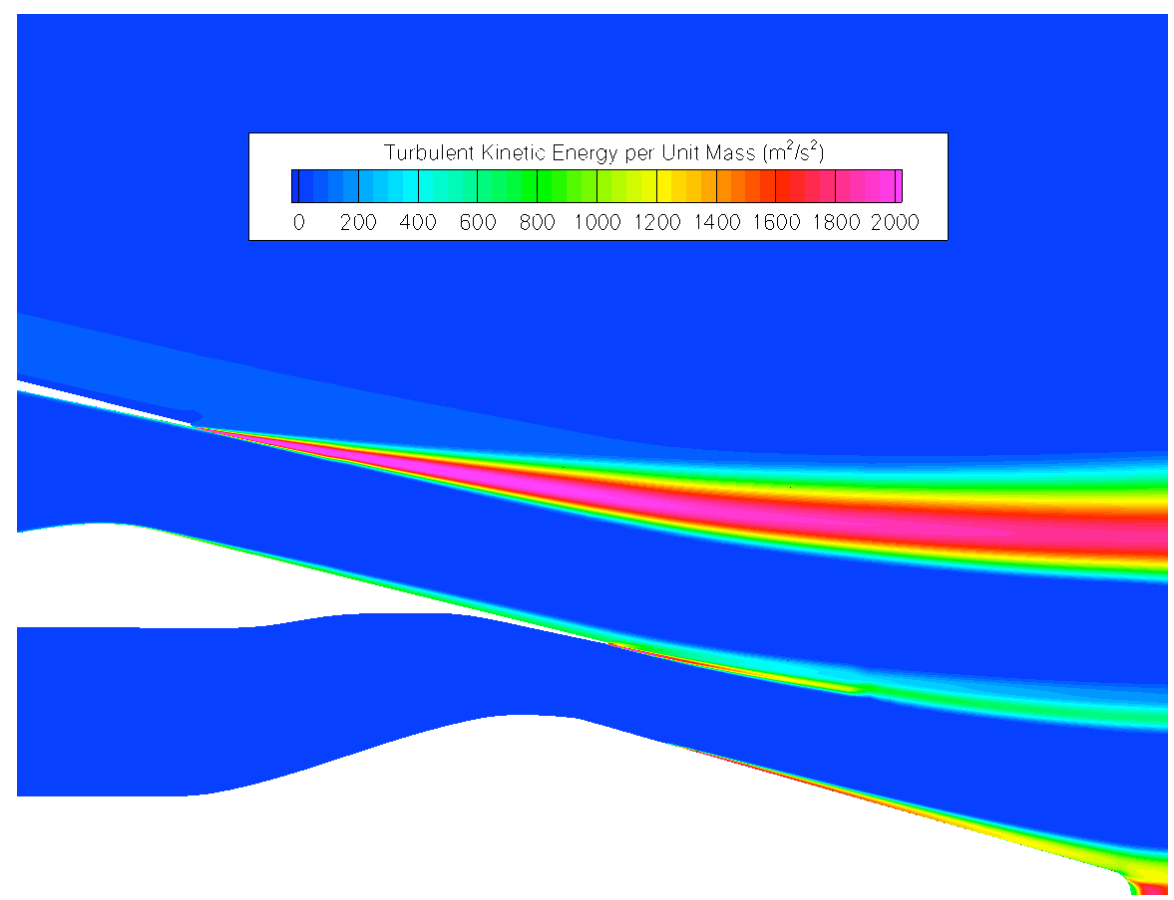

Figure 12: CF1 turbulent kinetic energy (TKE) per unit mass, PAB3D input data and structured mesh

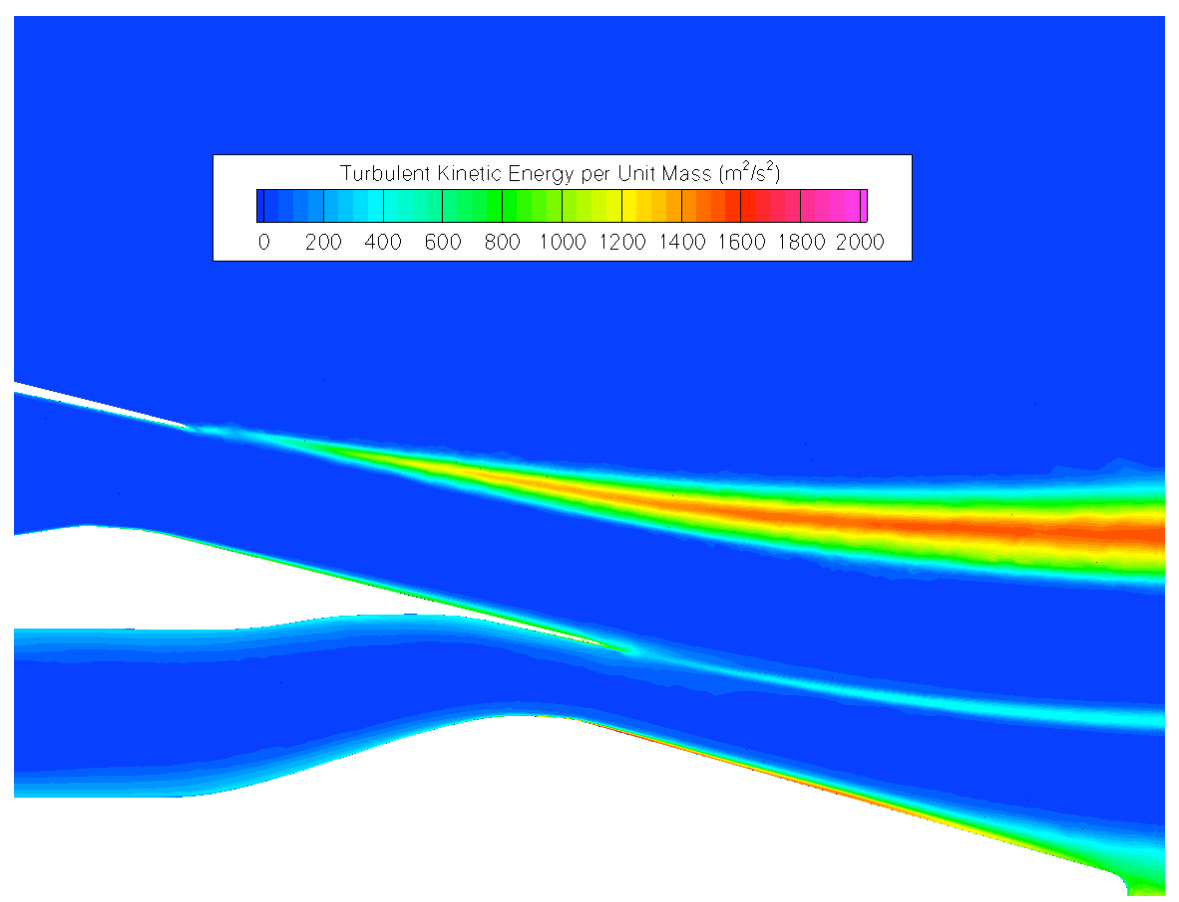

Figure 13: CF1 TKE per unit mass, USM3D input data and superfine adapted unstructured mesh 


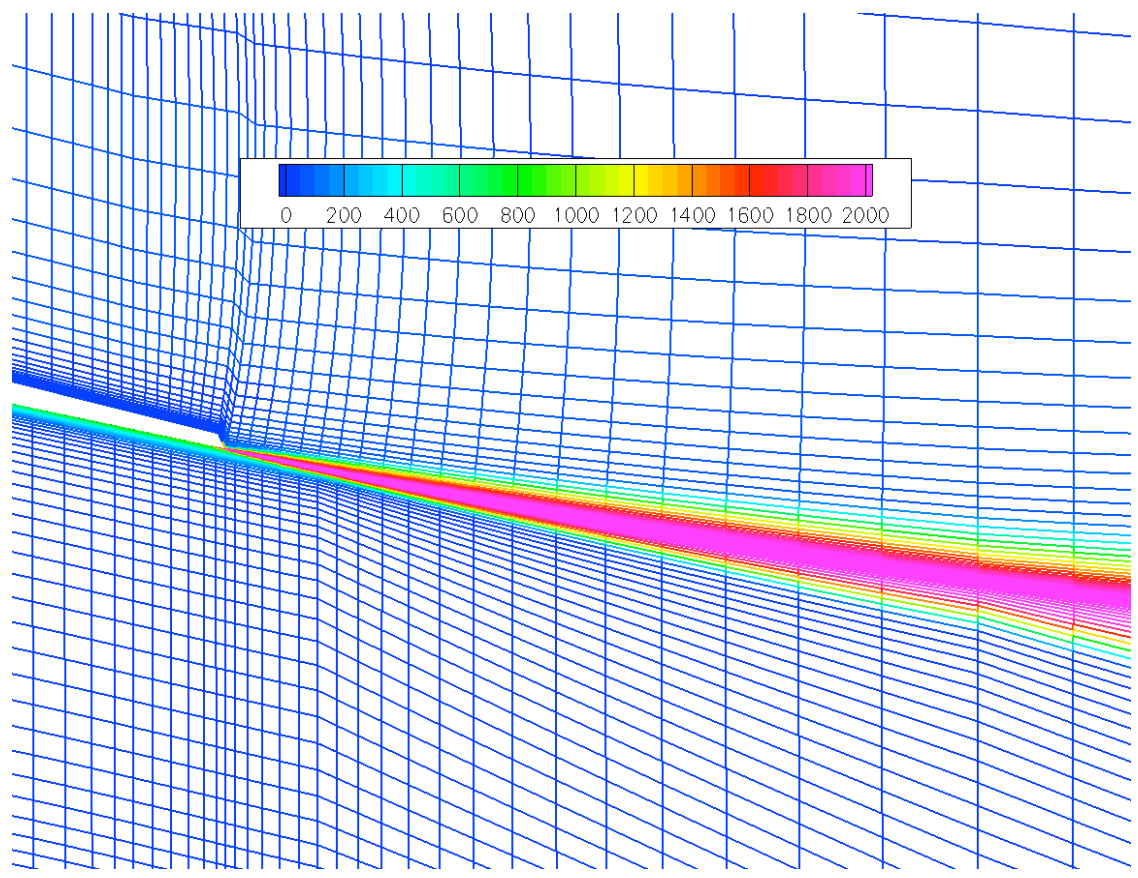

Figure 14: CF1 TKE per unit mass $\left(\mathrm{m}^{2} / \mathrm{s}^{2}\right)$ shown on mesh lines near fan nozzle lip, PAB3D

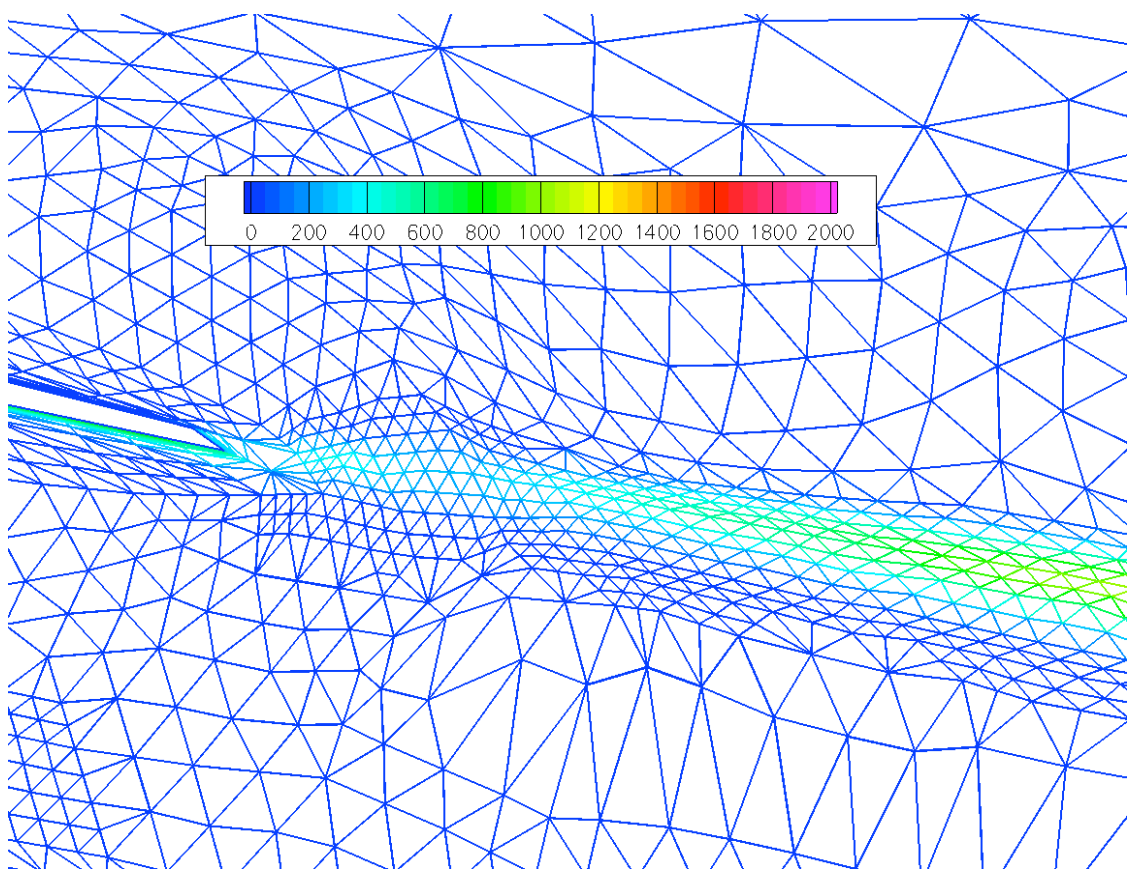

Figure 15: CF1 TKE per unit mass $\left(\mathrm{m}^{2} / \mathrm{s}^{2}\right)$ shown on mesh lines near fan nozzle lip, USM3D superfine 